\title{
Neighbour joining trees, dominant markers and population genetic structure
}

\author{
PM Hollingsworth ${ }^{1}$ and RA Ennos ${ }^{2}$ \\ ${ }^{1}$ Royal Botanic Garden, 20A Inverleith Row, Edinburgh EH3 5LR, UK; ${ }^{2}$ Institute of Cell and Population Biology, University of \\ Edinburgh, Darwin Building, King's Buildings, Mayfield Road, Edinburgh EH9 3JU, UK
}

\begin{abstract}
Population genetic theory for 'traditional' codominant loci showing low levels of allelic diversity (eg allozymes) has been well characterised and evaluated. In contrast, appropriate methods for the analysis of data from more recently developed marker systems are still being refined. For multilocus dominant markers such as amplified fragment length polymorphisms (AFLPs) and randomly amplified polymorphic DNA (RAPDs), the methods of data analysis can be split into two main categories. In population-based approaches, population allele frequencies are compared to obtain some measure of the partitioning of genetic diversity into within- and between-population components. In contrast, individual-based approaches use individual multilocus genotypes as the unit of analysis. Inferences on population processes such as gene flow are based on inter-relationships among individual samples as visualised on phenetic diagrams such as neighbour joining trees. Using a simulation approach coupled with neighbour joining analyses, we show
\end{abstract}

that while the underlying population genetic structure is an important determinant of tree shape in the analysis of dominant data, the number of loci examined also affects the topology. At low levels of population differentiation (eg $F_{\mathrm{ST}}=0.07$ ), mutually exclusive clustering of individuals into their respective populations can occur when sufficiently large numbers of loci are scored (eg 250 loci, typical of many AFLP studies). In contrast, unresolved star-shaped topologies can be recovered at higher levels of population differentiation $\left(F_{\mathrm{ST}}=>0.15\right)$ when lower numbers of loci are employed (eg 50 loci, typical of many RAPD studies). Thus, the relationship between tree topology and the extent of genetic structuring of populations is contingent upon the number of dominant loci scored. The consequences of these findings for the biological interpretation of individual-based analysis of dominant data sets are discussed.

Heredity (2004) 92, 490-498. advance online publication, 17 March 2004; doi:10.1038/sj.hdy.6800445

Keywords: RAPDs; AFLPs; ISSRs; $F_{\mathrm{ST}}$; population differentiation

\section{Introduction}

Traditional descriptors of population genetic structure (eg $F_{\mathrm{ST}}$ ) were developed for the analysis of population samples scored for genetic markers showing codominant inheritance and low levels of allelic diversity (typically two to four alleles per locus). A substantial body of population genetic theory appropriate for such markers has provided us with an understanding of how estimates of $F_{\mathrm{ST}}$ are influenced by parameters such as migration rate, population size and mutation rate (Wright, 1978; Nei, 1987). Using this knowledge, it is now possible (with caution, and making a number of assumptions) to infer biological processes such as dispersal patterns from estimates of $F_{\mathrm{ST}}$ calculated from traditional codominant markers (eg allozymes) in natural populations.

In recent years, a much wider range of genetic markers with significantly different properties have become available (Karp et al, 1998). These can be divided into two main classes: (1) locus-specific hypervariable microsatellite markers and (2) multilocus arbitrary fingerprinting techniques (eg randomly amplified polymorphic DNA (RAPDs), amplified fragment length polymorph-

Correspondence: P Hollingsworth, Royal Botanic Garden, 20A Inverleith Row, Edinburgh EH3 5LR, UK.

E-mail: P.Hollingsworth@rbge.org.uk

Received 14 April 2003; accepted 20 January 2004; published online 17 March 2004 isms (AFLPs)). The fact that both these classes of markers have different properties from their predecessors means that new methods of analysis are required if they are to be used to make inferences about population processes.

Microsatellite markers differ from allozyme markers in their stepwise pattern of mutation, their high mutation rates and their high levels of allelic diversity. Several recent reviews have highlighted the problems with using traditional estimators of $F_{\mathrm{ST}}$ derived from microsatellite data to infer such things as levels of gene flow among populations (Hedrick, 1999; Balloux et al, 2000; Balloux and LugonMoulin, 2002). This has stimulated the development of alternative methods that are based either on models of microsatellite evolution (eg $R_{\mathrm{ST}}$; Slatkin, 1995) or population assignment tests (Waser and Strobeck, 1998).

In the current paper, we focus on the analysis and interpretation of population data derived from arbitrary fingerprinting techniques such as RAPDs, ISSRs (intersimple sequence repeats) and AFLPs. These generate large numbers of polymorphic markers by the amplification or nonamplification of arbitrary DNA sequences scattered throughout the genome (Williams et al, 1990; Zietkiewicz et al, 1994; Vos et al, 1995). One clear advantage of these approaches is the large number of loci that can be scored as biallelic characters. RAPD and ISSR studies are typically based on data from 30 to 100 loci, whereas it is not unusual to score up to 250 loci in AFLP studies. The major disadvantage of using arbitrary 
fingerprinting techniques is the dominant nature of the data obtained (Lynch and Milligan, 1994; Harris, 1999). Of the three potential genotypic classes in a diploid individual $\left(X_{1} X_{1}, X_{1} X_{2}, X_{2} X_{2}\right)$, only two character states are recorded: band presence (scored as $1=X_{1} X_{1}$ and $\mathrm{X}_{1} \mathrm{X}_{2}$ ) and band absence (scored as $0=\mathrm{X}_{2} \mathrm{X}_{2}$ ).

Two strategies have been adopted for utilising this dominant suite of markers to study population structure. The first involves population level analysis. It requires scoring of substantial numbers of individuals across a range of populations. Where the breeding system of the populations is known, population allele frequencies can be estimated using appropriate unbiased estimators and $F_{\mathrm{ST}}$ is then determined (Lynch and Milligan, 1994). Alternatively, especially where the breeding system is not known, either a Bayesian approach to estimating $F_{\mathrm{ST}}$ can be performed (Holsinger et al, 2002) or a genetic distance matrix based on phenotypic data can be calculated, and the variation partitioned into its amongand between-population components to calculate an analogue of $F_{\mathrm{ST}}$ ( $\phi$ st; Excoffier et al, 1992). Inferences about levels of migration among populations, or population history, are then made in the normal way based on population genetic theory that relates $F_{\mathrm{ST}}$ to population processes.

The second strategy for utilising dominant marker data typically involves sampling a smaller number of individuals per population, but each is scored at a large number of loci. The multilocus dominant marker phenotypes of individuals are then used to generate a genetic distance matrix. This information is subjected to phenetic analysis to produce a visual representation (a tree-based diagram or principal coordinates plot (PCO)) of the genetic relationships among individuals in the sample (eg Winfield et al, 1998; Clausing et al, 2000; Drummond et al, 2000; van der Merwe et al, 2000; Sawkins et al, 2001; Barth et al, 2002; Nan et al, 2003).

The shape of the tree or PCO plot then forms the basis for making population genetic inferences about the populations from which the individuals were derived. For instance, grouping of individuals from different populations in the same cluster of a tree has been interpreted as evidence for gene flow between these populations; location of individuals from different populations in mutually exclusive clusters has been taken as evidence for genetic isolation of the populations.

The representation of genetic relationships among individuals using these techniques is commonly undertaken. However, the interpretation of the resulting trees in terms of the genetic behaviour of the populations involved is not straightforward, and is not based on any formal quantitative population genetic model or theory. Despite this, the use of phenetic diagrams using dominant data to infer population genetic processes appears to be gaining widespread and uncritical acceptance.

The objective of this paper is to emphasise some potential pitfalls inherent in this practice. To do this, we present a simple illustrative example. We explore how the commonly used neighbour joining tree-based approach for analysing arbitrary fingerprinting data relates to known information on population structure. We show how variation in the extent of genetic differentiation among populations, the number of markers scored and the interaction of these factors affect tree topology. Our purpose is not to provide guidelines for population genetic interpretation of phenetic trees, but rather to emphasise some factors that make this process problematic when practised in isolation.

\section{Materials and methods}

\section{Overview}

The procedure adopted can be divided into four steps:

(1) An individual-based computer model simulates the genetic behaviour of some populations isolated to different degrees. The populations are polymorphic at a large number of selectively neutral, unlinked loci (250). This number is chosen because it is close to the upper limit of the number of loci routinely included in population genetic studies using dominant markers. The simulation generates multilocus codominant genotypes of all individuals in the populations.

(2) Traditional population genetic methods are then used to quantify the partitioning of genetic variation between populations by calculating $F_{\mathrm{ST}}$ using all of the codominant data.

(3) The same codominant data are then converted to multilocus dominant phenotypes. A genetic distance matrix among individuals is then calculated and used to generate a neighbour joining tree. To illustrate the effect of using different numbers of dominant genetic markers, data from either all 250 or subsamples of 125 and 50 loci are used to construct neighbour joining trees.

(4) The extent to which individuals from different populations are clustered on distinct tree branches is then assessed, and compared with the quantitative measure of the partitioning of genetic information between populations $\left(F_{\mathrm{ST}}\right) . F_{\mathrm{ST}}$ estimates from the full codominant data set represent a well-understood standard, against which the tree-based analyses of the dominant data are compared.

\section{Simulation of genetic drift}

Simulations were performed using the individual-based discrete generation model Easypop1.7.1 (Balloux, 1999). All populations simulated contained 100 diploid, random mating individuals. At the beginning of each simulation, populations were polymorphic at 250 unlinked, codominant, selectively neutral, diallelic loci $(X)$ in which the frequency of both alleles $\left(X_{1}, X_{2}\right)$ was 0.5 . Genetic divergence between populations was then generated in two ways:

(i) Divergence in isolation: Genetic drift was simulated in two populations (designated A and B) genetically isolated for up to 75 generations. Multilocus, codominant genotypes of all individuals in the two populations were stored from independent simulations at five-generation intervals from five to 75 generations.

(ii) Divergence with migration: Each simulation involved 10 populations. Drift and migration between populations occurred under an island model with zygotic migration at a rate $m$ per generation. 
Simulated values of $m$ varied from $0.0025(\mathrm{Nm}=0.25$ migrants per generation) to 0.08 ( $N m=8$ migrants per generation). The migration rates represent the probability of any one individual being a migrant (ie the rates are not deterministic). Simulations were run for 100 generations. Two populations (designated $\mathrm{A}$ and $\mathrm{B}$ ) were then selected at random from the 10 in the simulation. The complete multilocus codominant genotypes from all 200 individuals in these two populations were used in subsequent analyses.

All simulations were replicated five times.

\section{Calculation of $F_{\mathrm{ST}}$}

$F_{\mathrm{ST}}$, measuring the partitioning of genetic variation between the two populations was calculated from the complete codominant multilocus data set using GENEPOP 3.3. (Raymond and Rousset, 1995). F $F_{\mathrm{ST}}$ values derived from our simulations of populations diverging in isolation were compared with the expected $F_{\mathrm{ST}}$ values:

$$
F_{\mathrm{ST}}=1-(1-1 / 2 N)^{t}
$$

where $t$ is the number of generations of isolation (Weir, 1996).

\section{Individual tree-based analysis}

Codominant multilocus data from all 200 individuals were converted to dominant data using the convention $X_{1} X_{1}=1, X_{1} X_{2}=1, X_{2} X_{2}=0$, where 1 represents the presence and 0 represents the absence of a band in a typical RAPD, ISSR or AFLP analysis. This approach is designed to mimic sampling of diploid individuals using dominant markers.

Two approaches were used to construct distance matrices among individuals. In the first, we used a simple Euclidean distance measure:

$$
E=n\left[1-\left(n_{x y} / n\right)\right]
$$

where $n$ is the total number of polymorphic bands and $n_{x y}$ is the number of characters shared by individuals $x$ and $y$ (shared presences and shared absences). This approach has been used by many authors for arbitrary fingerprinting data in both tree- and AMOVA-based analyses (eg Ayres and Ryan, 1997; Arens et al, 1998; Carino and Daehler, 1999; Greef and Triest, 1999; Amsellem et al, 2000; Comes and Abbott, 2000; Auge et al, 2001).

The use of Euclidean distances has been criticised on the grounds that the shared absence of a band may be attributable to multiple different factors and is not necessarily a homologous character state (Harris, 1999). However, this is not an issue in our simulations where sharing of the character states 1 or 0 represent true homologies (the simulations start with a biallelic system at panmixia with no subsequent mutation; there is no homoplasy).

Nevertheless, we also calculated distance among individuals using Jaccard's (1908) similarity coefficient (calculated in $\mathrm{R}$ version 4.0 (Casgrain and Legendre, 2001) and imported into PAUP* as a user-specified distance). This is an asymmetrical distance that excludes shared band absence (Harris, 1999). Jaccard's distance $=1-S$, where

$$
\mathrm{S}=a /(a+b+c)
$$

and $a$ is the number of bands shared between accessions $x$ and $y, b$ is the number of bands in accession $x$ and $c$ is the number of bands in accession $y$.

Neighbour joining trees (Saitou and Nei, 1987) were constructed for each simulation from matrices of Euclidean distances and corresponding Jaccard's coefficients and visualised as unrooted phylograms using PAUP* (Swofford, 2000). Not surprisingly, given the 'clean' nature of the simulated data, virtually identical results were obtained. We report here only the results using the Euclidean metric. Separate trees were calculated using information from 250, 125 or 50 loci. The population identity of each individual (A or B) was indicated on the tree.

\section{Results}

\section{Classification of tree types}

The trees generated by the neighbour joining analysis could be classified into three classes, represented in Figure 1. In the first (Star, Figure 1a), individuals from the two populations $A$ and $B$ were intermingled. In the second, significant structure was apparent, but up to $5 \%$ of individuals were included within the cluster occupied by the alternate population (misclassified (Mc), Figure $1 \mathrm{~b}$ ). In the third type of tree, individuals from populations A and B were clearly separated in different clusters (mutually exclusive (ME), Figure 1c). These categories were subsequently used as a convenient shorthand for describing the outcome of neighbour joining tree analysis under different population and sampling scenarios.

a

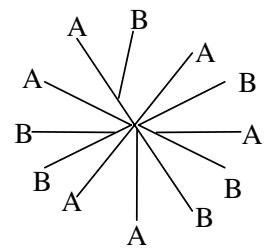

Star

b

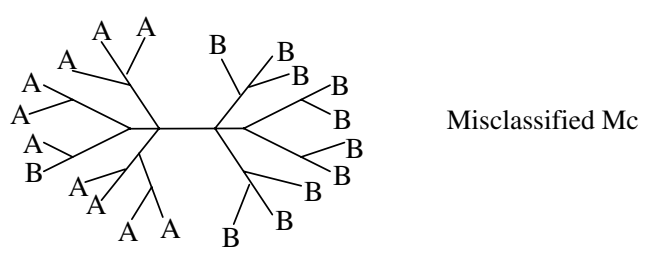

C

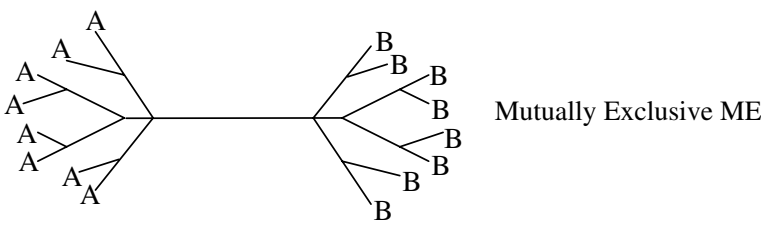

Figure 1 Stylised trees to illustrate different topologies among individuals from each of 2 populations (A and B). (a) Shows an unresolved 'star'-shaped topology. (b) Shows the two populations falling into two groups, but with one Mc individual. (c) Shows ME clustering of the individuals from the two populations. 
$F_{\mathrm{ST}}$ and tree shape after genetic divergence in isolation Figure 2 summarises the comparison of $F_{\mathrm{ST}}$ values and tree shape when two populations diverge in isolation (the raw data is presented in Appendix A). As anticipated, the $F_{\mathrm{ST}}$ value rises as the number of generations in isolation between the two populations increases. The $F_{\mathrm{ST}}$ values derived from our simulations match closely the expected values (Appendix A).

For 250 loci, when the populations diverged for five generations $\left(F_{\mathrm{ST}}=0.02-0.025\right)$, a star-shaped topology was recovered (Figure 2). Greater structure was observed, however, after only 10 generations in isolation $\left(F_{\mathrm{ST}}=0.046-0.052\right)$ with less than 10 individuals being Mc in each simulation. After 15 generations, and at low values of $F_{\mathrm{ST}}\left(\mathrm{eg} F_{\mathrm{ST}}=0.072-0.078\right)$, the individuals fell into ME clusters.

For 125 loci the star-shaped topologies still occur for up to 10 generations in isolation $\left(F_{\mathrm{ST}}=0.046-0.052\right)$, and Mc individuals occurred for up to 45 generations $\left(F_{\mathrm{ST}}=0.187\right)$ (Figure 2$)$. ME clustering occurred in some simulations after 20 generations $\left(F_{\mathrm{ST}}=0.090\right)$, but only after approximately 30 generations $\left(F_{\mathrm{ST}}=0.124-0.132\right)$ did this pattern predominate.

For 50 loci, the star-shaped topology was the predominant topology for up to 25 generations approxi-
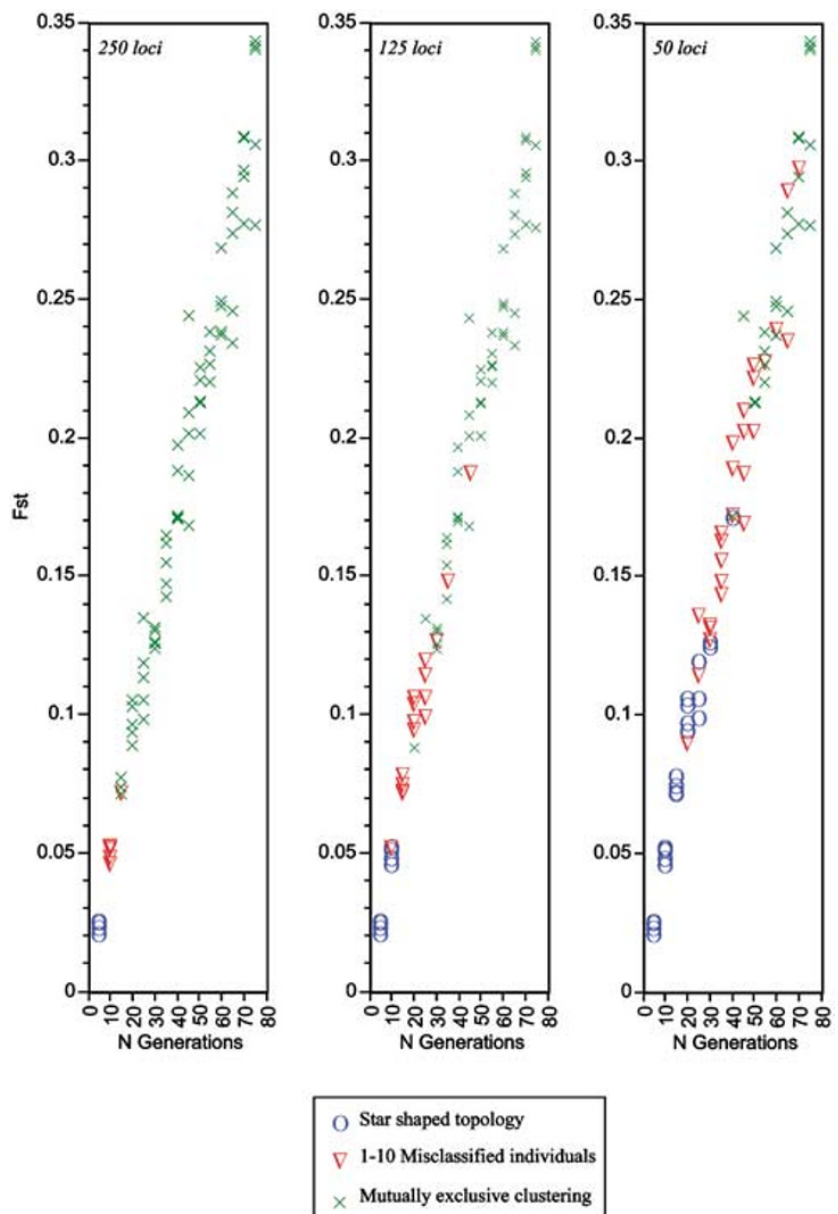

Figure 2 Relationship between $F_{\mathrm{ST}}$ and tree shape for two populations diverging in isolation for five to 75 generations, analysed for 250, 125 and 50 loci, respectively. mately in isolation $\left(F_{\mathrm{ST}}=\right.$ ca. 0.1$)$, and occurred for up to 40 generations in isolation $\left(F_{\mathrm{ST}}=0.171\right)$ (Figure 2$)$. Mc individuals occurred at high $F_{\mathrm{ST}}$ values (eg $F_{\mathrm{ST}}=0.297$; up to 70 generations in isolation).

As the number of loci scored decreases, the transition to the ME tree type occurs after a greater number of generations, and at a higher $F_{\mathrm{ST}}$ value (Figure 2 ). The tree shape obtained for a given level of genetic divergence thus depends on the number of loci scored. In addition, as the number of loci used for constructing the trees decreases, the variance increases, such that the transition zones between the different tree topologies (star-Mc$\mathrm{ME}$ ) become more diffuse with fewer loci (Figure 2).

\section{$F_{\mathrm{ST}}$ and tree shape under divergence with migration}

Table 1 shows the results of individual simulations with migration rates ranging from 0.0025 to 0.08 . It is important to stress that for these simulations there are two sources of Mc individuals. These correspond to (a) individuals with multilocus genotypes that are by chance more similar to those from the foreign population than their own population and (b) immigrant individuals.

For 250 loci for high migration rates $(\mathrm{Nm}>6$ per generation) a star topology is found. For intermediate migration rates $(6>N m>1)$ the tree topologies tend to be structured, with variable numbers of individuals Mc (Mc type). For low migration rates and high $F_{\mathrm{ST}}$ values $\left(F_{\mathrm{ST}}>0.25 ; N m<0.05\right)$ individuals from the two populations tend to fall into ME clusters (ME type). Table 2 shows the expected numbers of migrants for the different migration rates. It can be seen that the number of $\mathrm{Mc}$ individuals at intermediate migration rates broadly corresponds to the expected number of immigrants (Table 2).

As was the case for divergence in isolation, as the number of loci decreases, a greater level of population differentiation (in this case lower migration rates) is required before the transition from a star-shaped topology to ME clustering occurs. For 125 loci, starshaped topologies are recovered until a migration rate of 0.02 and an $F_{\mathrm{ST}}=0.081$ are reached (Table 1). For 50 loci, star-shaped topologies were recovered up to a migration rate of 0.015 and an $F_{\mathrm{ST}}=0.124$ (Table 1).

\section{Discussion}

The simulations described here indicate that it is inadvisable to draw population genetic inferences solely from the topology of neighbour joining trees generated from distance matrices based on arbitrary fingerprinting data. As the simulations illustrate, there is no straightforward relationship between genetic isolation and the partitioning of genetic variation among populations on the one hand, and clustering of individuals on the neighbour joining tree on the other. The results are contingent on the number of markers scored.

When a very large number of markers are available, as in AFLP analyses, clustering of groups can occur at very low $F_{\mathrm{ST}}$ values. In the simulation of two populations diverging in isolation with 250 loci, very strong structuring (ME type) is shown between populations when the $F_{\text {ST }}$ value is only 0.07 (Figure 2). As the number of loci used decreases, ME clustering occurs at increasingly higher levels of population differentiation. For 250 loci, the highest $F_{\mathrm{ST}}$ value at which there is a Mc 
Table 1 Relationship between migration rate, $F_{\mathrm{ST}}$ and tree topology from simulated data under divergence with migration

\begin{tabular}{|c|c|c|c|c|}
\hline \multirow[t]{2}{*}{ Migration rate } & \multirow[t]{2}{*}{$\mathrm{F}_{S T}$} & \multicolumn{3}{|c|}{ Tree shape } \\
\hline & & 250 loci & 125 loci & 50 loci \\
\hline 0.0025 & 0.3231 & ME & ME & ME \\
\hline 0.0025 & 0.3334 & ME & ME & ME \\
\hline 0.0025 & 0.2746 & $1 \mathrm{Mc}$ & $2 \mathrm{Mc}$ & $2 \mathrm{Mc}$ \\
\hline 0.0025 & 0.2920 & ME & ME & $1 \mathrm{Mc}$ \\
\hline 0.0025 & 0.3499 & ME & ME & ME \\
\hline 0.005 & 0.2506 & $\mathrm{ME}$ & ME & $1 \mathrm{Mc}$ \\
\hline 0.005 & 0.2319 & $1 \mathrm{Mc}$ & $1 \mathrm{Mc}$ & $3 \mathrm{Mc}$ \\
\hline 0.005 & 0.2511 & ME & ME & $7 \mathrm{Mc}$ \\
\hline 0.005 & 0.2437 & $1 \mathrm{Mc}$ & $1 \mathrm{Mc}$ & $2 \mathrm{Mc}$ \\
\hline 0.005 & 0.2353 & $1 \mathrm{Mc}$ & $1 \mathrm{Mc}$ & $1 \mathrm{Mc}$ \\
\hline 0.01 & 0.1943 & ME & ME & $3 \mathrm{Mc}$ \\
\hline 0.01 & 0.1770 & ME & $2 \mathrm{Mc}$ & $6 \mathrm{Mc}$ \\
\hline 0.01 & 0.1528 & ME & $2 \mathrm{Mc}$ & $4 \mathrm{Mc}$ \\
\hline 0.01 & 0.1690 & ME & ME & $2 \mathrm{Mc}$ \\
\hline 0.01 & 0.1721 & $1 \mathrm{Mc}$ & ME & $2 \mathrm{Mc}$ \\
\hline 0.015 & 0.1238 & $1 \mathrm{Mc}$ & $8 \mathrm{Mc}$ & Star \\
\hline 0.015 & 0.1527 & $1 \mathrm{Mc}$ & $1 \mathrm{Mc}$ & $4 \mathrm{Mc}$ \\
\hline 0.015 & 0.1264 & $2 \mathrm{Mc}$ & $2 \mathrm{Mc}$ & Star \\
\hline 0.015 & 0.1256 & $1 \mathrm{Mc}$ & $4 \mathrm{Mc}$ & $9 \mathrm{Mc}$ \\
\hline 0.015 & 0.1141 & $2 \mathrm{Mc}$ & $3 \mathrm{Mc}$ & $6 \mathrm{Mc}$ \\
\hline 0.02 & 0.1078 & $5 \mathrm{Mc}$ & $5 \mathrm{Mc}$ & Star \\
\hline 0.02 & 0.1173 & $2 \mathrm{Mc}$ & $3 \mathrm{Mc}$ & $10 \mathrm{Mc}$ \\
\hline 0.02 & 0.1059 & $5 \mathrm{Mc}$ & $3 \mathrm{Mc}$ & Star \\
\hline 0.02 & 0.1132 & $1 \mathrm{Mc}$ & $2 \mathrm{Mc}$ & $6 \mathrm{Mc}$ \\
\hline 0.02 & 0.0808 & $6 \mathrm{Mc}$ & Star & Star \\
\hline 0.03 & 0.0614 & $6 \mathrm{Mc}$ & $8 \mathrm{Mc}$ & Star \\
\hline 0.03 & 0.0704 & $8 \mathrm{Mc}$ & Star & Star \\
\hline 0.03 & 0.0579 & $7 \mathrm{Mc}$ & Star & Star \\
\hline 0.03 & 0.0656 & $5 \mathrm{Mc}$ & Star & Star \\
\hline 0.03 & 0.0579 & $7 \mathrm{Mc}$ & Star & Star \\
\hline 0.04 & 0.0497 & Star & Star & Star \\
\hline 0.04 & 0.0531 & $8 \mathrm{Mc}$ & Star & Star \\
\hline 0.04 & 0.0614 & $9 \mathrm{Mc}$ & Star & Star \\
\hline 0.04 & 0.0533 & $9 \mathrm{Mc}$ & Star & Star \\
\hline 0.04 & 0.0481 & Star & Star & Star \\
\hline 0.06 & 0.0360 & $10 \mathrm{Mc}$ & Star & Star \\
\hline 0.06 & 0.0337 & Star & Star & Star \\
\hline 0.06 & 0.0317 & Star & Star & Star \\
\hline 0.06 & 0.0335 & Star & Star & Star \\
\hline 0.06 & 0.0250 & Star & Star & Star \\
\hline 0.08 & 0.0307 & Star & Star & Star \\
\hline 0.08 & 0.0303 & Star & Star & Star \\
\hline 0.08 & 0.0294 & Star & Star & Star \\
\hline 0.08 & 0.0202 & Star & Star & Star \\
\hline 0.08 & 0.0267 & Star & Star & Star \\
\hline
\end{tabular}

Star $=$ star-shaped topologies; $\mathrm{Mc}=$ between 1 and 10 misclassified individuals (with the number of $\mathrm{Mc}$ individuals specified) $\mathrm{ME}=$ mutually exclusive clusters.

individual for divergence in isolation is $F_{\mathrm{ST}}=0.0715$, for 125 loci it is $F_{\mathrm{ST}}=0.1873$ and for 50 loci it is $F_{\mathrm{ST}}=0.297$ (Figure 2, Appendix A). There is also an increasing amount of noise, and the transitions between the different tree topologies becomes more protracted with fewer loci.

In the absence of any knowledge of $F_{\mathrm{ST}}$ an intuitive interpretation of strong structure in a neighbour joining tree may be that the populations involved are genetically isolated. Yet, this is not the case. Where large numbers of loci are scored structured trees are produced after a small number of generations in isolation (eg 10, Figure 2), or with up to one migrant per generation (Table 1). Indeed, the chances of finding structured trees may be even higher than suggested by our simulations. The reason is
Table 2 Expected and observed number of misclassified individuals for differing migration rates

\begin{tabular}{lccccc}
\hline $\begin{array}{l}\text { Migrants per } \\
\text { population per } \\
\text { generation }\end{array}$ & $\begin{array}{c}\text { Expected } \\
\text { Mc }\end{array}$ & \multicolumn{3}{c}{ Observed } & Mean $\mathrm{F}_{S T}$ \\
\cline { 2 - 5 } & & 250 loci & 125 loci & 50 loci & \\
\hline 0.25 & 0.5 & 0.2 & 0.4 & 0.6 & 0.3146 \\
0.5 & 1 & 0.6 & 0.6 & 2.8 & 0.2425 \\
1 & 2 & 0.2 & 0.8 & 3.4 & 0.1730 \\
1.5 & 3 & 1.4 & 3.6 & Star & 0.1285 \\
2 & 4 & 3.8 & 5.4 & Star & 0.1050 \\
3 & 6 & 6.6 & Star & Star & 0.0626 \\
4 & 8 & Star & Star & Star & 0.0531 \\
6 & 12 & Star & Star & Star & 0.0320 \\
8 & 16 & Star & Star & Star & 0.0275 \\
\hline
\end{tabular}

Expected number of Mc individuals is the expected number of immigrants in each population. The observed number of misclassified individuals and the mean $F_{\mathrm{ST}}$ estimates are based on five simulations at each migration rate.

that in the results reported here, all individuals in the population were included in the neighbour joining trees. In a typical field-based study, only a proportion of individuals would be sampled. Under these circumstances, the probability of sampling recent migrants would be low, and the distinctions between groups might appear even more pronounced on the neighbour joining tree at low levels of $F_{\mathrm{ST}}$.

This problem with overestimating the genetic distinctiveness of groups is likely to increase in the future. Our simulations used between 50 and 250 loci. However, as the automation of fragment analyses improves and the costs of techniques such as AFLPs come down, the number of markers used in empirical population level studies is likely to increase (eg Cresswell et al, 2001 used 765 polymorphic loci in their AFLP analysis of Lolium diversity). In these circumstances neighbour joining trees may be able to distinguish groups between which genetic divergence is so small as to be biologically insignificant.

This must be borne in mind when data such as these are used in any applied context to guide genetic management of populations. Just because individuals from two separate populations form ME clusters in a neighbour joining tree, this does not necessarily imply that there is no gene exchange, or that, in a conservation scenario, the populations should be treated as different units for management.

Although the simulations have highlighted problems with simple genetic interpretations of tree topology, they nevertheless suggest that when large numbers of markers are available it may be possible to recognise recent migrants within populations from their multilocus genotypes and assign them to their source population (Waser and Strobeck, 1998). Thus in the drift-migration simulations, the number of ' $\mathrm{Mc}^{\prime}$ individuals within populations corresponds well with the number of migrants anticipated in the previous generation. And while it is known that simple phenetic-based methods of assignment such as this are weak, it supports the notion that the use of more formalised assignment tests for the study of population genetic processes represents a potentially useful application of the resolving power of large numbers of polymorphic molecular markers (Waser and Strobeck, 1998; Pritchard et al, 2000). 
We stress that the results presented here (tree shape in relation to $F_{\mathrm{ST}}$ for a given number of polymorphic markers) do not form the basis for direct extrapolation based on 'real' data (eg obtaining an estimate of $F_{\mathrm{ST}}$ from the shape of a tree and a known number of polymorphic markers). (1) Firstly, the simulated data are clean; all 1's and all 0's are homologous. Real data will contain varying levels of noise attributable to comigrating nonhomologous bands and, if Euclidean distances are used, nonhomologous shared absences. The level of this noise in the data will be an additional contributing factor in the determination of tree topology. (2) The results presented here are for panmictic random mating sub-populations. Localised subpopulation differentiation and/or selfing may lead to marked multilocus structure among individuals that will affect their relationships in an individual-based clustering diagram for a given value of $F_{\mathrm{ST}}$. (3) Our starting frequency of alleles for each locus was 0.5. In real data sets, lowfrequency variants at individual loci are likely to alter the power of discrimination between populations for a given number of polymorphic loci. (4) The number of simulations we have carried out have been sufficient to illustrate clearly the differences between tree topologies when the same individuals are scored for different numbers of loci. The number of simulations undertaken was not designed to estimate formally the mean and variance of $F_{\mathrm{ST}}$ values under which these topology transitions occur (and given the previously mentioned caveats in the interpretation of our simulation results, any such estimates would be of doubtful biological relevance).

Instead, our take home message is that simple population genetic interpretation of phenetic cluster diagrams is problematical. In addition to the underlying population genetic structure, a key determinant of tree shape is the number of loci analysed. The same biological situation can result in different tree topologies if studied with different numbers of markers. While this fact may come as no surprise to many population geneticists, the prevalence of this approach, especially in the plant molecular ecology literature, suggests that the limitations involved deserve wider appreciation.

\section{Acknowledgements}

We are grateful to the members of our research groups at ICAPB and RBGE for constructive discussion on the analysis of dominant data, and to Deborah Charlesworth and journal reviewers for helpful comments on an earlier draft of this paper. The Royal Botanic Garden Edinburgh is supported by the Scottish Executive Environmental and Rural Affairs Department.

\section{References}

Amsellem L, Noyer JL, Bourgeois TL (2000). Comparison of genetic diversity of the invasive weed Rubus alceifolius Poir. (Rosaceae) in its native range and in areas of introduction, using amplified fragment length polymorphism (AFLPs) markers. Mol Ecol 9: 443-455.

Arens P, Coops H, Jansen J, Vosman B (1998). Molecular genetic analysis of black poplar (Populus nigra L.) along Dutch rivers. Mol Ecol 7: 11-18.
Auge H, Neuffer B, Erlinghagen F, Grupe R, Brandl R (2001). Demographic and random amplified polymorphic DNA analyses reveal high levels of genetic diversity in a clonal violet. Mol Ecol 10: 1811-1819.

Ayres DR, Ryan FJ (1997). The clonal and population structure of a rare endemic plant, Wyethia reticulata (Asteraceae): allozyme and RAPD analysis. Mol Ecol 6: 761-772.

Balloux F (1999). EASYPOP, a software for population genetics simulation. Available via http://www.unil.ch/izea/softwares/ easypop.html.

Balloux F, Brünner H, Lugon-Moulin N, Hausser J, Goudet J (2000). Microsatellites can be misleading: an empirical and simulation study. Evolution 54: 1414-1422.

Balloux F, Lugon-Moulin N (2002). The estimation of population differentiation with microsatellite markers. Mol Ecol 11 155-165.

Barth S, Melchinger AE, Lübberstedt T (2002). Genetic diversity in Arabidopsis thaliana L. Heynh. investigated by cleaved amplified polymorphic sequence (CAPS) and inter-simple sequence repeat (ISSR) markers. Mol Ecol 11: 495-505.

Carino DA, Daehler CC (1999). Genetic variation in an apomictic grass, Heteropogon contortus, in the Hawaiian Islands. Mol Ecol 8: 2127-2132.

Casgrain P, Legendre P (2001). The R Package for Multivariate and Spatial Analysis. Version 4.0 d5 - User's Manual. Département de sciences biologiques, Université de Montréal, Montréal, Available via http://www.fas.umontreal.ca/BIOL/legendre/.

Clausing G, Vickers K, Kadereit JW (2000). Historical biogeography in a linear system: genetic variation of Sea Rocket (Cakile maritima) and Sea Holly (Eryngium maritimum) along European coasts. Mol Ecol 9: 1823-1833.

Comes HP, Abbott RJ (2000). Random amplified polymorphic DNA (RAPD) and quantitative trait analyses across a major phylogeographic break in the Mediterranean ragwort Senecio gallicus Vill. (Asteraceae). Mol Ecol 9: 61-76.

Cresswell A, Sackville-Hamilton NR, Roy AK, Viegas BMF (2001). Use of amplified fragment length polymorphism markers to assess genetic diversity of Lolium species from Portugal. Mol Ecol 10: 229-241.

Drummond RSM, Keeling DJ, Richardson TE, Gardner RC, Wright SD (2000). Genetic analysis and conservation of 31 surviving individuals of a rare New Zealand tree, Metrosideros bartlettii (Myrtaceae). Mol Ecol 9: 1149-1157.

Excoffier L, Smouse P, Quattro J (1992). Analysis of molecular variance inferred from metric distance among DNA haplotypes: application to human mitochondrial DNA restriction data. Genetics 131: 479-491.

Greef BD, Triest L (1999). The use of random amplified polymorphic DNA (RAPD) for hybrid detection in Scirpus from the river Schelde (Belgium). Mol Ecol 8: 379-386.

Harris SA (1999). RAPDs in systematics - a useful methodology? In: Hollingsworth PM, Bateman RM, Gornall RJ (eds) Molecular Systematics and Plant Evolution. Taylor \& Francis: London, pp 211-228.

Hedrick PW (1999). Highly variable loci and their interpretation in evolution and conservation. Evolution 53: 313-318.

Holsinger KE, Lewis PO, Dey DK (2002). A Bayesian approach to inferring population structure from dominant markers. Mol Ecol 11: 1157-1164.

Jaccard P (1908). Nouvelles recherches sur la distribution florale. Bull Soc Vaud des Sci Nat 44: 223-270.

Karp A, Isaac PG, Ingram DS (eds) (1998). Molecular Tools for Screening Biodiversity: Plants and Animals. Chapman \& Hall: London.

Lynch M, Milligan BG (1994). Analysis of population genetic structure with RAPD markers. Mol Ecol 3: 91-100.

Nan P, Shi S, Peng S, Tian C, Zhong Y (2003). Genetic diversity in Primula obconica (Primulaceae) from Central South-west China as revealed by ISSR markers. Ann Bot (Lond) 91: 329-333.

Nei M (1987). Molecular Evolutionary Genetics. Columbia University Press: New York. 
Pritchard JK, Stephens M, Donnelly P (2000). Inference of population structure using multilocus genotypic data. Genetics 155: 945-959.

Raymond M, Rousset F (1995). GENEPOP: population genetics software for exact tests and ecumenicism. J Hered 86: 248-249.

Saitou M, Nei M (1987). The neighbor-joining method: A new method for reconstructing phylogenetic trees. Mol Biol Evol 4: 406-425.

Sawkins MC, Maass BL, Pengelly BC, Newbury HJ, Ford-Lloyd BV, Maxted N et al (2001). Geographical patterns of genetic variation in two species of Stylosanthes Sw. using amplified fragment length polymorphism. Mol Ecol 10: 1947-1958.

Slatkin M (1995). A measure of population subdivision based on microsatellite allele frequencies. Genetics 139: 457-462.

Swofford DL (2000). PAUP* 4.0 beta 4a. Phylogenetic Analysis Using Parsimony (and Other Methods). Sinauer Associates: Sunderland, MA.

van der Merwe M, Winfield MO, Arnold GM, Parker JS (2000) Spatial and temporal aspects of the genetic structure of Juniperis communis populations. Mol Ecol 9: 379-386.

Vos P, Hogers R, Bleeker M, Reijans M, van der Lee T, Hornes M et al (1995). A new technique for DNA-fingerprinting. Nucleic Acids Res 23: 4407-4414.

Waser PM, Strobeck C (1998). Genetic signatures of interpopulation dispersal. Trends Ecol Evol 13: 43-44.
Weir BS (1996). Genetic Data Analysis II. Sinauer: Sunderland MA.

Williams JGK, Kubelik AR, Livak KJ, Rafalski JA, Tingey SV (1990). DNA polymorphisms amplified by arbitrary primers are useful as genetic markers. Nucleic Acids Res 18: 6531-6535.

Winfield MO, Arnold GM, Cooper F, Le-Ray M, White J, Karp A (1998). A study of genetic diversity in Populus nigra subsp. betulifolia in the Upper Severn area of the UK using AFLP markers. Mol Ecol 7: 3-10.

Wright S (1978). Evolution and Genetics of Populations. Vol. 4. Variability Within and Among Populations. University of Chicago Press: Chicago.

Zietkiewicz E, Rafalski A, Labuda D (1994). Genome fingerprinting by simple sequence repeat (SSR)-anchored polymerase chain reaction amplification. Genomics 20: 176-183.

\section{Appendix A}

Results from individual simulations (as summarised in Figure 2) on the relationship between $F_{\mathrm{ST}}$ and tree topology from simulated data for two populations diverging in isolation. The observed $F_{\mathrm{ST}}$ values are from our simulations, the expected $F_{\mathrm{ST}}$ values are derived from $F_{\mathrm{ST}}=1-(1-1 / 2 N)^{t}$, where $t$ is the number of generations of isolation (Weir, 1996), as seen in Table A1.

Table A1 Results from individual simulations (as summarised in Figure 2) on the relationship between $F_{\mathrm{ST}}$ and tree topology from simulated data for two populations

\begin{tabular}{|c|c|c|c|c|c|}
\hline \multirow[t]{2}{*}{ Generations in isolation } & \multirow[t]{2}{*}{ Observed $\mathrm{F}_{S T}$} & \multirow[t]{2}{*}{ Expected $\mathrm{F}_{S T}$} & \multicolumn{3}{|c|}{ Number of loci } \\
\hline & & & 250 loci & 125 loci & 50 loci \\
\hline 5 & 0.0229 & & Star & Star & Star \\
\hline 5 & 0.0255 & & Star & Star & Star \\
\hline 5 & 0.0254 & & Star & Star & Star \\
\hline \multirow[t]{2}{*}{5} & 0.0249 & & Star & Star & Star \\
\hline & Mean 0.0247 & 0.0248 & & & \\
\hline 10 & 0.052 & & $4 \mathrm{Mc}$ & Star & Star \\
\hline 10 & 0.0461 & & $8 \mathrm{Mc}$ & Star & Star \\
\hline 10 & 0.0509 & & $1 \mathrm{Mc}$ & Star & Star \\
\hline 10 & 0.0483 & & $4 \mathrm{Mc}$ & Star & Star \\
\hline \multirow[t]{2}{*}{10} & 0.0519 & & $1 \mathrm{Mc}$ & $8 \mathrm{Mc}$ & Star \\
\hline & Mean 0.0498 & 0.0489 & & & \\
\hline 15 & 0.0715 & & $1 \mathrm{Mc}$ & $3 \mathrm{Mc}$ & Star \\
\hline 15 & 0.0746 & & ME & $1 \mathrm{Mc}$ & Star \\
\hline 15 & 0.0746 & & ME & $7 \mathrm{Mc}$ & Star \\
\hline 15 & 0.0721 & & ME & $5 \mathrm{Mc}$ & Star \\
\hline \multirow[t]{2}{*}{15} & 0.0780 & & $\mathrm{ME}$ & $4 \mathrm{Mc}$ & Star \\
\hline & Mean 0.0742 & 0.0724 & & & \\
\hline 20 & 0.0944 & & $\mathrm{ME}$ & $1 \mathrm{Mc}$ & Star \\
\hline 20 & 0.1059 & & ME & $2 \mathrm{Mc}$ & Star \\
\hline 20 & 0.1037 & & ME & $1 \mathrm{Mc}$ & Star \\
\hline 20 & 0.0972 & & ME & $1 \mathrm{Mc}$ & Star \\
\hline \multirow[t]{2}{*}{20} & 0.0896 & & $\mathrm{ME}$ & ME & $6 \mathrm{Mc}$ \\
\hline & Mean 0.0982 & 0.0954 & & & \\
\hline 25 & 0.1061 & & ME & $1 \mathrm{Mc}$ & Star \\
\hline 25 & 0.1192 & & $\mathrm{ME}$ & $2 \mathrm{Mc}$ & Star \\
\hline 25 & 0.0987 & & ME & $1 \mathrm{Mc}$ & Star \\
\hline 25 & 0.1139 & & $\mathrm{ME}$ & $1 \mathrm{Mc}$ & $5 \mathrm{Mc}$ \\
\hline 25 & 0.1358 & & $\mathrm{ME}$ & $\mathrm{ME}$ & $5 \mathrm{Mc}$ \\
\hline
\end{tabular}


Table A1 (continued)

\begin{tabular}{lccc}
\hline Generations in isolation & Observed $\mathrm{F}_{S T}$ & Expected $\mathrm{F}_{S T}$ & Number of loci \\
\cline { 3 - 4 } & & 250 loci & 125 loci loci \\
\hline
\end{tabular}

Mean 0.1147

$$
\begin{aligned}
& 0.1248 \\
& 0.1312 \\
& 0.1267 \\
& 0.1262 \\
& 0.1323
\end{aligned}
$$

Mean 0.1282

$$
\begin{aligned}
& 0.1654 \\
& 0.1431 \\
& 0.1481 \\
& 0.1553 \\
& 0.1626
\end{aligned}
$$

Mean 0.1549

0.1725

0.1890

0.1720

0.1980

0.1711

Mean 0.1805

$$
\begin{aligned}
& 0.2021 \\
& 0.1873 \\
& 0.1691 \\
& 0.2446 \\
& 0.2097
\end{aligned}
$$

Mean 0.2026

$$
\begin{aligned}
& 0.2261 \\
& 0.2216 \\
& 0.2021 \\
& 0.2133 \\
& 0.2139
\end{aligned}
$$

Mean 0.2154

0.2317

0.2391

0.2270

0.2210

0.2274

Mean 0.2292

$$
\begin{aligned}
& 0.2484 \\
& 0.2500 \\
& 0.2391 \\
& 0.2379 \\
& 0.2693
\end{aligned}
$$

Mean 0.2489

$$
\begin{aligned}
& 0.2820 \\
& 0.2892 \\
& 0.2748 \\
& 0.2464 \\
& 0.2347
\end{aligned}
$$

Mean 0.2654

0.1178

$$
\begin{aligned}
& \text { ME } \\
& \text { ME } \\
& \text { ME } \\
& \text { ME }
\end{aligned}
$$

0.1396

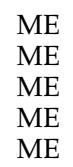

0.1609

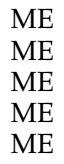

0.1817

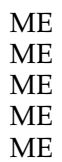

0.2019

$$
\begin{aligned}
& \text { ME } \\
& \text { ME } \\
& \text { ME } \\
& \text { ME }
\end{aligned}
$$

ME

0.2217

ME
ME
ME
ME
ME

0.2410

$$
\begin{aligned}
& \text { ME } \\
& \text { ME } \\
& \text { ME } \\
& \text { ME } \\
& \text { ME }
\end{aligned}
$$

0.2597

$$
\begin{aligned}
& \text { ME } \\
& \text { ME } \\
& \text { ME } \\
& \text { ME } \\
& \text { ME }
\end{aligned}
$$

0.2781

ME

$M E$

$\mathrm{ME}$
$\mathrm{ME}$
$\mathrm{ME}$
$1 \mathrm{Mc}$
$\mathrm{ME}$

Star

$1 \mathrm{Mc}$

$4 \mathrm{Mc}$

Star

$6 \mathrm{Mc}$

$2 \mathrm{Mc}$

$7 \mathrm{Mc}$

$4 \mathrm{Mc}$

$2 \mathrm{Mc}$

$2 \mathrm{Mc}$

$\begin{array}{ll}\mathrm{ME} & 2 \mathrm{Mc} \\ \mathrm{ME} & 2 \mathrm{Mc}\end{array}$

$\begin{array}{lc}\text { ME } & \text { ME } \\ \text { ME } & 1 \mathrm{Mc} \\ \text { ME } & 3 \mathrm{Mc} \\ \text { ME } & 9 \mathrm{Mc} \\ \text { ME } & \text { Star }\end{array}$

$\begin{array}{cc}\mathrm{ME} & 8 \mathrm{Mc} \\ 1 \mathrm{Mc} & 2 \mathrm{Mc} \\ \mathrm{ME} & 1 \mathrm{Mc} \\ \mathrm{ME} & \mathrm{ME} \\ \mathrm{ME} & 2 \mathrm{Mc}\end{array}$

$\begin{array}{lc}\mathrm{ME} & 1 \mathrm{Mc} \\ \mathrm{ME} & 1 \mathrm{Mc} \\ \mathrm{ME} & 3 \mathrm{Mc} \\ \mathrm{ME} & \mathrm{ME} \\ \mathrm{ME} & \mathrm{ME}\end{array}$

$\begin{array}{lc}M E & M E \\ M E & M E \\ M E & M E \\ M E & M E \\ M E & 2 \mathrm{Mc}\end{array}$

$\begin{array}{lc}\text { ME } & \text { ME } \\ \text { ME } & M E \\ M E & 1 \mathrm{Mc} \\ \text { ME } & M E \\ \text { ME } & \text { ME }\end{array}$

$\begin{array}{lc}\text { ME } & \mathrm{ME} \\ \mathrm{ME} & 2 \mathrm{Mc} \\ \mathrm{ME} & \mathrm{ME} \\ \mathrm{ME} & \mathrm{ME} \\ \mathrm{ME} & 5 \mathrm{Mc}\end{array}$

$\begin{array}{lc}\text { ME } & \text { ME } \\ \text { ME } & 1 \mathrm{Mc}\end{array}$

Table A1 Continued.. 
Table A1 (continued)

\begin{tabular}{|c|c|c|c|c|c|}
\hline \multirow[t]{2}{*}{ Generations in isolation } & \multirow[t]{2}{*}{ Observed $\mathrm{F}_{S T}$} & \multirow[t]{2}{*}{ Expected $\mathrm{F}_{S T}$} & \multicolumn{3}{|c|}{ Number of loci } \\
\hline & & & 250 loci & 125 loci & 50 loci \\
\hline 70 & 0.2782 & & ME & ME & ME \\
\hline 70 & 0.2952 & & ME & ME & ME \\
\hline \multirow[t]{2}{*}{70} & 0.3087 & & ME & ME & ME \\
\hline & Mean 0.2978 & 0.2959 & & & \\
\hline 75 & 0.3068 & & ME & ME & ME \\
\hline 75 & 0.3424 & & ME & ME & ME \\
\hline 75 & 0.3413 & & ME & ME & ME \\
\hline 75 & 0.2772 & & ME & ME & ME \\
\hline \multirow[t]{2}{*}{75} & 0.3442 & & $\mathrm{ME}$ & ME & ME \\
\hline & Mean 0.3224 & 0.3134 & & & \\
\hline
\end{tabular}

